(c) American Dairy Science Association, 2003.

\title{
Selective Enumeration of Lactobacillus delbrueckii ssp. bulgaricus, Streptococcus thermophilus, Lactobacillus acidophilus, Bifidobacteria, Lactobacillus casei, Lactobacillus rhamnosus, and Propionibacteria
}

\author{
N. Tharmaraj and N. P. Shah \\ School of Molecular Sciences \\ Victoria University, Werribee Campus \\ PO Box 14428 Melbourne City Mail Centre, Victoria 8001 Australia
}

\begin{abstract}
Nineteen bacteriological media were evaluated to assess their suitability to selectively enumerate Lactobacillus delbrueckii ssp. bulgaricus, Streptococcus thermophilus, Lactobacillus casei, Lactobacillus rhamnosus, Lactobacillus acidophilus, bifidobacteria, and propionibacteria. Bacteriological media evaluated included Streptococcus thermophilus agar, $\mathrm{pH}$ modified MRS agar, MRS-vancomycine agar, MRS-bile agar, MRS$\mathrm{NaCl}$ agar, MRS-lithium chloride agar, MRS-NNLP (nalidixic acid, neomycin sulfate, lithium chloride and paramomycine sulfate) agar, reinforced clostridial agar, sugar-based (such as maltose, galactose, sorbitol, manitol, esculin) media, sodium lactate agar, arabinose agar, raffinose agar, xylose agar, and L. casei agar. Incubations were carried out under aerobic and anaerobic conditions at $27,30,37,43$, and $45^{\circ} \mathrm{C}$ for $24,72 \mathrm{~h}$, and 7 to $9 \mathrm{~d}$. S. thermophilus agar and aerobic incubation at $37^{\circ} \mathrm{C}$ for $24 \mathrm{~h}$ were suitable for $S$. thermophilus. $L$. delbrueckii ssp. bulgaricus could be enumerated using MRS agar ( $\mathrm{pH} 4.58$ or $\mathrm{pH} 5.20$ ) and under anaerobic incubation at $45^{\circ} \mathrm{C}$ for $72 \mathrm{~h}$. MRS-vancomycine agar and anaerobic incubation at $43^{\circ} \mathrm{C}$ for $72 \mathrm{~h}$ were suitable to enumerate $L$. rhamnosus. MRS-vancomycine agar and anaerobic incubation at $37^{\circ} \mathrm{C}$ for $72 \mathrm{~h}$ were selective for $L$. case $i$. To estimate the counts of $L$. case $i$ by subtraction method, counts of $L$. rhamnosus on MRS-vancomycine agar at $43^{\circ} \mathrm{C}$ for $72 \mathrm{~h}$ under anaerobic incubation could be subtracted from total counts of $L$. case $i$ and $L$. rhamnosus enumerated on MRS-vancomycine agar at $37^{\circ} \mathrm{C}$ for 72 $\mathrm{h}$ under anaerobic incubation. L. acidophilus could be enumerated using MRS-agar at $43^{\circ} \mathrm{C}$ for $72 \mathrm{~h}$ or Basal agar-maltose agar at $43^{\circ} \mathrm{C}$ for $72 \mathrm{~h}$ or BA-sorbitol agar at $37^{\circ} \mathrm{C}$ for $72 \mathrm{~h}$, under anaerobic incubation. Bifidobacteria could be enumerated on MRS-NNLP agar under anaero-
\end{abstract}

Received August 16, 2001.

Accepted January 15, 2003.

Corresponding author: N. P. Shah; e-mail: Nagendra.Shah@ vu.edu.au. bic incubation at $37^{\circ} \mathrm{C}$ for $72 \mathrm{~h}$. Propionibacteria could be enumerated on sodium lactate agar under anaerobic incubation at $30^{\circ} \mathrm{C}$ for 7 to $9 \mathrm{~d}$. A subtraction method was most suitable for counting propionibacteria in the presence of other lactic acid bacteria from a product. For this method, counts of lactic bacteria at $\mathrm{d} 3$ on sodium lactate agar under anaerobic incubation at $30^{\circ} \mathrm{C}$ were subtracted from counts at $d 7$ of lactic bacteria and propionibacteria.

(Key words: Lactobacillus acidophilus, Lactobacillus casei, Lactobacillus rhamnosus, propionibacteria).

Abbreviation key: BA = basal agar, $\mathbf{N N L P}=$ nalidixic acid, neomycine sulfate, lithium chloride and paromomycine sulfate, ST agar = Streptococcus thermophilus agar, $\mathbf{R C A}=$ reinforced clostridial agar, $\mathbf{R S M}=$ reconstituted skim milk.

\section{INTRODUCTION}

A number of health benefits have been claimed for probiotic bacteria and more than 90 probiotic products containing one or more groups of probiotic organisms are available worldwide. Probiotic food can be defined as "food containing live microorganisms which actively enhance the health of consumers by improving the balance of microflora in the gut" (Fuller, 1992).

A number of probiotic organisms including L. acidophilus, Bifidobacterium spp., Lactobacillus casei, Lactobacillus rhamnosus, and Propionibacterium are incorporated in dairy foods. These organisms grow slowly in milk during product manufacture. Therefore the usual practice is to incorporate yogurt bacteria (Streptococcus thermophilus and Lactobacillus delbrueckii ssp. bulgaricus) along with probiotic cultures. Yogurt bacteria do not survive in the gastric passage or colonize in the gut (Shah and Jelen, 1990) and are unlikely to provide any therapeutic benefits. However, yogurt bacteria grow rapidly and thus are added to speed up the fermentation process.

To provide health benefits, the suggested concentration for probiotic bacteria is $10^{6} \mathrm{cfu} / \mathrm{g}$ of a product (Shah, 2000). It seems reasonable to assume that the beneficial 
effects of probiotic bacteria can be expected only when viable cells are ingested. An important parameter in monitoring viable organisms in assessing product quality is the ability to count probiotic bacteria differentially. Differential enumeration of probiotic bacteria is difficult owing to the presence of several types of similar microbes in a product. In order to assess viability and survival of probiotic bacteria, it is important to have a working method for selective enumeration of these bacteria.

Several media for selective enumeration of $L$. acidophilus and Bifidobacterium spp. have been previously proposed (Hunger, 1986; Hull and Roberts, 1984; Laroia and Martin, 1991; Dave and Shah, 1996; Lankaputhra and Shah, 1996; Wijsman et al., 1989; Shah, 1997, 2000). Similarly, several media have been proposed for selective enumeration of yogurt cultures (Onggo and Fleet, 1993; Samona and Robinson, 1984). There are only few reports that have described selective enumeration of Lactobacillus casei in the presence of other probiotic bacteria and yogurt bacteria (Champagne et al., 1997; Ravula and Shah, 1998). Selective enumeration of $L$. casei from probiotic products based on a $15^{\circ} \mathrm{C}$ incubation temperature and 14 day incubation was studied by Champagne et al. (1997). Ravula and Shah (1998) developed a medium, known as LC agar, for selective enumeration of $L$. casei. Selective enumeration of Lactobacillus reuteri, Lactobacillus plantarum, Lactobacillus rhamnosus, and propionibacteria has not been studied extensively. The aim of this study was to develop and evaluate media for selective enumeration of $S$. thermophilus, L. delbrueckii ssp. bulgaricus, L. acidophilus, L. casei, L. rhamnosus, bifidobacteria, and propionibacteria.

\section{MATERIALS AND METHODS}

\section{Bacteria Cultures and Propagation}

L. delbrueckii ssp. bulgaricus (LB 100B), S. thermophilus (ST 2362), L. casei (DS 930), L. acidophilus (DS 910), Bifidobacterium lactis (DS920), and Propionibacterium freudenreichii ssp. globosum (type standard 10360) were provided by DSM Gist brocades (DSM Gist brocade Australia Pty. Ltd., Werribee, Australia). L. paracasei ssp. paracasei (LC01), L. acidophilus (LA 5), Bifidobacterium lactis (Bb 12), and Propionibacterium freudenreichii ssp. shermanii (PS1) were obtained from Chr. Hansen (Chr. Hansen Pty. Ltd., Bayswater, Australia). L. rhamnosus (LC 705), L. acidophilus (74-2), and Bifidobacterium spp. (BB 420) were received from Danisco Cultor (Danisco Cultor, Dingley, Australia). S. thermophilus (TA040), L. paracasei ssp. paracasei (LBC81), L. rhamnosus (LBA), L. acidophilus (LAC 4), and Bifidobacterium spp. (BL) were from Rhodia (Rhodia Australia Pty. Ltd., Notting Hill, Australia).
All the strains were tested for purity using Gram stain. All cultures except propionibacteria were propagated weekly in sterile $12 \%$ reconstituted skim milk (RSM) supplemented with $2 \%$ glucose and $1.2 \%$ yeast extract. Cultures were grown using $1 \%$ inoculum at $37^{\circ} \mathrm{C}$ for 18 h. Propionibacteria were grown in sodium lactate broth (composition: $10 \mathrm{~g}$ of pancreatic digest of casein, $10 \mathrm{~g}$ of sodium lactate, $10 \mathrm{~g}$ of yeast extract, $0.5 \mathrm{~g}$ of Tween 80 , and $1 \mathrm{~L}$ of distilled water) and incubated at $30^{\circ} \mathrm{C}$ for 2 d using $1 \%$ inoculum. Bifidobacteria were propagated using $1 \%$ inoculum in sterile RSM supplemented with $0.05 \%$ L-cysteine-hydrochloride in order to provide anaerobic condition and to enhance their growth. Cultures were maintained in the same media at $4^{\circ} \mathrm{C}$. Before enumeration the cultures were transferred successively three times for activation.

\section{Media Preparation}

Bacteriological peptone and water diluent. Bacteriological peptone and water diluent $(0.15 \%)$ were prepared by dissolving $1.5 \mathrm{~g}$ of bacteriological peptone (Oxoid (Australia) Pty. Ltd., West Heidleberg, Australia) in $1 \mathrm{~L}$ of distilled water. The $\mathrm{pH}$ was adjusted to $7.0 \pm 0.2$, followed by autoclaving $9 \mathrm{ml}$ aliquots at $121^{\circ} \mathrm{C}$ for $15 \mathrm{~min}$.

Streptococcus thermophilus (ST) agar. The ST agar was prepared according to the method described by Dave and Shah (1996).

MRS agar, pH-modified (pH 5.20, 4.58) MRS agar, MRS-vancomycine agar, MRS-bile (0.2\% and 0.5\%) agar, MRS-NaCl agar, and MRS lithium chloride agar. Rehydrated MRS broth (Oxoid) was prepared according to the manufacturer instructions. The $\mathrm{pH}$ of the broth was adjusted to 5.20 and 4.58 using $1.0 \mathrm{M} \mathrm{HCl}$ to obtain the $\mathrm{pH}$-modified agar. Two and five grams of pure bile salts (Amyl Media, Dandenong Australia)/L were added to obtain $0.2 \%$ and $0.5 \%$ MRS-bile agar. Forty grams of $\mathrm{NaCl} / \mathrm{L}$ was added for MRS-NaCl agar (4\% final concentration) and $5 \mathrm{~g} / \mathrm{L}$ lithium chloride $(\mathrm{LiCl})$ was added for MRS-LiCl agar (0.5\% final concentration). To prepare MRS-vancomycine (MRS-V) agar, $2 \mathrm{ml}$ of 0.05 $\mathrm{g}$ vancomycine (Sigma Chemical Co., Castle Hill, Australia)/100 ml solution was added to $1 \mathrm{~L}$ of MRS broth to obtain $1 \mathrm{mg} / \mathrm{L}$ final concentration. Agar powder was added to each broth at the rate of $1.2 \%$ and the media were autoclaved at $121^{\circ} \mathrm{C}$ for $15 \mathrm{~min}$. Inoculated plates in duplicates were incubated anaerobically at $37^{\circ} \mathrm{C}$ and $43^{\circ} \mathrm{C}$ for $72 \mathrm{~h}$.

MRS-NNLP agar. The MRS-nalidixic acid, neomycine sulfate, lithium chloride and paromomycine sulfate agar (NNLP; Sigma Chemical Co.) was prepared according to the method described by Laroia and Martin (1991). MRS agar was the basal medium. Filter-sterilized NNLP was added to the autoclaved MRS base just 
Table 1. Viable counts $\left(\log _{10} \mathrm{cfu} / \mathrm{g}\right)$ and colony size of bacterial cultures in different sugar-based media (anaerobic incubation, $37^{\circ} \mathrm{C}, 72 \mathrm{~h}$ ).

\begin{tabular}{|c|c|c|c|c|c|c|c|c|c|c|c|c|}
\hline \multirow[b]{2}{*}{ Cultures } & \multicolumn{2}{|c|}{ MRS } & \multicolumn{2}{|c|}{$\mathrm{BA}^{1}$-maltose } & \multicolumn{2}{|c|}{ BA-galactose } & \multicolumn{2}{|c|}{ BA-sorbitol } & \multicolumn{2}{|c|}{ BA-mannitol } & \multicolumn{2}{|c|}{ BA-esculin } \\
\hline & Counts & Size $(\mathrm{mm})$ & Counts & Size $(\mathrm{mm})$ & Counts & Size $(\mathrm{mm})$ & Counts & Size $(\mathrm{mm})$ & Counts & Size (mm) & Counts & Size $(\mathrm{mm})$ \\
\hline LB-LB 100B & 8.28 & $0.1-0.5$ & $<3.00$ & - & - & - & $<3.00$ & - & $<3.00$ & - & $<3.00$ & - \\
\hline ST-DS 2362 & 8.09 & $0.5 \mathrm{~mm}$ & $<3.00$ & - & $<3.00$ & - & $<3.00$ & - & $<3.00$ & - & $<3.00$ & - \\
\hline LC-DS 930 & 9.30 & 2.0 & 9.48 & 2.0 & 9.30 & 2.0 & 9.23 & 2.0 & 9.42 & 2.0 & 9.21 & 2.0 \\
\hline LC-LCO 1 & 9.28 & 2.0 & 8.30 & 2.0 & 9.15 & 2.0 & 9.23 & 2.0 & 9.23 & 2.0 & 9.21 & $1.0-1.5$ \\
\hline LC-LBC 81 & 9.07 & 2.0 & 9.34 & 2.0 & 9.18 & 2.0 & 9.28 & 2.0 & 9.22 & 2.0 & 9.22 & $1.0-1.5$ \\
\hline LA-LA 5 & 7.00 & $0.1-0.5$ & 8.00 & $0.5-1$ & 7.70 & $0.5-1$ & 8.09 & $0.1-0.5$ & 7.43 & $0.1-0.5$ & 7.50 & $0.1-0.5$ \\
\hline LA-DS 910 & 8.41 & $0.5-1$ & 8.59 & $1.0-1.5$ & 8.30 & $1.0-1.5$ & 8.70 & $0.1-0.5$ & 9.18 & $0.1-0.5$ & 7.83 & $0.1-0.5$ \\
\hline LA-LAC 4 & 7.15 & $0.1-0.5$ & 7.13 & $0.5-1.0$ & 7.19 & $.5-1$ & 7.08 & $0.1-0.5$ & 7.10 & $0.1-0.5$ & 7.84 & $0.1-0.5$ \\
\hline LA-74-2 & 7.11 & $0.1-0.5$ & 8.81 & $0.5-1.0$ & 7.26 & $.5-1$ & 8.08 & $0.1-0.5$ & 7.20 & $0.1-0.5$ & 7.24 & $0.1-0.5$ \\
\hline BB-Bb 12 & $<3.00$ & - & $<3.00$ & - & $<3.00$ & - & $<3.00$ & - & $<3.00$ & - & 9.26 & $1.0-1.5$ \\
\hline BB-DS 920 & $<3.00$ & - & $<3.00$ & - & $<3.00$ & - & $<3.00$ & - & $<3.00$ & - & 8.95 & $1.0-1.5$ \\
\hline BB-420 & $<3.00$ & - & $<3.00$ & - & $<3.00$ & - & $<3.00$ & - & $<3.00$ & - & 8.88 & $1.0-1.5$ \\
\hline
\end{tabular}

${ }^{1} \mathrm{BA}=$ Basal agar, $\mathrm{LB}=$ L. delbrueckii $\mathrm{ssp}$. bulgaricus, $\mathrm{ST}=S$. thermophilus, $\mathrm{LC}=$ L. casei, $\mathrm{LA}=$ L. acidophilus, $\mathrm{LR}=$ L. rhamnosus, $\mathrm{BB}$ = Bifidobacterium, PS = Propionibacterium freudenreichii ssp. shermanii .

before pouring. Filter-sterilized L-cysteine-HCl $(0.05 \%$ final concentration) was also added at the same time to lower the oxidation-reduction potential of the medium and to enhance the growth of anaerobic bifidobacteria. Inoculated plates in duplicates were incubated anaerobically at $37^{\circ} \mathrm{C}$ for $72 \mathrm{~h}$.

Reinforced clostridial agar. Reinforced clostridial agar (RCA; Oxoid) was made according to the manufacturer instructions and sterilized by autoclaving at $121^{\circ} \mathrm{C}$ for $15 \mathrm{~min}$.

Basal agar, BA-maltose agar, BA-galactose agar, BA-sorbitol agar, BA-mannitol agar, and BA-esculin agar. Basal agar was prepared (composition: $10 \mathrm{~g}$ of trypton, $10 \mathrm{~g}$ of Lablemco powder, $5 \mathrm{~g}$ of yeast extract, $1 \mathrm{~g}$ of Tween 80, $2.6 \mathrm{~g}$ of $\mathrm{K}_{2} \mathrm{HPO}_{4}, 5 \mathrm{~g}$ of sodium acetate, $2 \mathrm{~g}$ of tri-ammonium citrate, $0.2 \mathrm{~g}$ of $\mathrm{MgSO}_{4} \cdot 7 \mathrm{H}_{2} \mathrm{O}, 0.05$ $\mathrm{g}$ of $\mathrm{MnSO}_{4} \cdot 4 \mathrm{H}_{2} \mathrm{O}, 12 \mathrm{~g}$ of bacteriological agar, and $1 \mathrm{~L}$ of distilled water) and autoclaved at $121^{\circ} \mathrm{C}$ for $15 \mathrm{~min}$. Ten milliliters of membrane filtered sterile $20 \%$ solutions of maltose, galactose, sorbitol, mannitol or esculin were added to $90 \mathrm{ml}$ of basal agar (2\% final concentration) just before pouring the agar medium. Inoculated plates in duplicates were incubated aerobically and anaerobically at $37^{\circ} \mathrm{C}$ and $43^{\circ} \mathrm{C}$ for $72 \mathrm{~h}$.

Sodium lactate agar (NaLa agar), arabinose agar, xylose agar, and raffinose agar. The base for these agar media was prepared (composition: $10 \mathrm{~g}$ of pancreatic digest of casein, $10 \mathrm{~g}$ of yeast extract, $2 \mathrm{~g}$ of sodium pyruvate, $2 \mathrm{~g}$ of glycine, $1.5 \mathrm{~g}$ of sodium chloride, $0.5 \mathrm{~g}$ of Tween 80, $0.25 \mathrm{~g}$ of di-potasium hydrogen phosphate, $12 \mathrm{~g}$ of bacteriological agar and $1 \mathrm{~L}$ of distilled water). The $\mathrm{pH}$ was adjusted to $7 \pm 0.2$ using $1 M \mathrm{HCl}$ and $10 M \mathrm{NaOH}$. To make NaLa agar, $10 \mathrm{~g}$ of sodium lactate was added before autoclaving. The medium was then autoclaved at $121^{\circ} \mathrm{C}$ for $15 \mathrm{~min}$. For other media, $10 \mathrm{ml}$ of $10 \%$ membrane filtered arabinose, raffinose or xylose was added to $90 \mathrm{ml}$ of autoclaved media (1\% final concentration) before pouring the plates. Inoculated plates in duplicates were incubated anaerobically at $30^{\circ} \mathrm{C}$ for 7 to $9 \mathrm{~d}$.

LC agar. LC agar was made using the method described by Ravula and Shah (1998). The incubation was carried out under anaerobic condition at $27^{\circ} \mathrm{C}$ for $72 \mathrm{~h}$.

\section{Enumeration of Bacteria}

Cultures were activated by three successive transfers in nutrient medium before enumeration. One gram of each culture was 10 -fold serially diluted $\left(10^{3}\right.$ to $\left.10^{7}\right)$ in $0.15 \%$ sterile bacteriological peptone and water diluents. Enumeration was carried out using the pour plate technique. Anaerobic jars and gas generating kits (Anaerobic System, BR 38; Oxoid Ltd., Hampshire, England) were used for creating anaerobic condition. Plates containing 25 to 250 colonies were enumerated and recorded as colony forming units (cfu) per gram of the product or culture.

All experiments and analyses were repeated at least twice. The results presented are averages of at least two replicates.

\section{RESULTS AND DISCUSSION}

Viable counts $\left(\log _{10} \mathrm{cfu} / \mathrm{g}\right)$ and colony sizes (in $\mathrm{mm}$ diameter) of 7 species of bacterial cultures containing 18 
strains of bacteria including 1 strain of $L$. delbrueckii ssp. bulgaricus, 2 strains of $S$. thermophilus, 3 strains of $L$. casei, 2 strains of $L$. rhamnosus, 4 strains of $L$. acidophilus, 4 strains of Bifidobacterium spp., and 2 strains of propionibacteria in various sugar based media are presented in Table 1. L. delbrueckii ssp. bulgaricus did not grow in any sugar-based media except in MRS agar. MRS agar was particularly suitable for growing lactobacilli. $S$. thermophilus did not grow in any sugar based medium and formed small colonies in MRS agar.

RCA agar supported the growth of all tested organisms. Bifidobacteria grew in this medium even without the addition of L-cysteine.hydrochloride (data not shown). Therefore RCA agar was not suitable for selective enumeration.

ST agar was found to be suitable for $S$. thermophilus (data not shown). S. thermophilus formed tiny (0.1-0.5 $\mathrm{mm}$ ) colonies in ST agar at $37^{\circ} \mathrm{C}$ under aerobic incubation after $24 \mathrm{~h}$. The incubation time was insufficient for growth of other cultures even if ST agar did not inhibit the growth of other organisms. Therefore, ST agar at $37^{\circ} \mathrm{C}$ for $24 \mathrm{~h}$ and aerobic condition were selective for $S$. thermophilus. This is in agreement with a previous report (Dave and Shah, 1996).

Other organisms such as, L. casei, L. rhamnosus and $L$. acidophilus grew in all sugar-based media. Bifidobacteria did not grow in any media, except in BA-esculin agar. Propionibacterium freudenreichii ssp. shermanii grew only in MRS agar and BA-galactose agar. Thus based on sugar utilization patterns, probiotic organisms could not be selectively enumerated.

Table 2 shows the counts of bacterial cultures in media containing different inhibitory substances including vancomycine, NNLP, hydrochloric acid, $\mathrm{NaCl}, \mathrm{LiCl}$, and bile at $37^{\circ} \mathrm{C}$ and $43^{\circ} \mathrm{C}$ incubations. All the organisms except Bifidobacterium spp. grew in MRS agar. When the $\mathrm{pH}$ of MRS agar was reduced to 5.20 and the incubation temperature increased to $43^{\circ} \mathrm{C}$, only $L$. delbrueckii ssp. bulgaricus (which formed $1.0 \mathrm{~mm}$, white rough irregular colonies), L. rhamnosus (which formed $2 \mathrm{~mm}$, shiny smooth white colonies) and L. acidophilus (which formed 0.1 to $0.5 \mathrm{~mm}$, brown, rough irregular colonies) showed good growth. When the $\mathrm{pH}$ of MRS agar was reduced to 4.58 using $1 \mathrm{M} \mathrm{HCl}$, only $L$. delbrueckii ssp. bulgaricus and $L$. rhamnosus showed good growth similar to that formed in MRS agar at $\mathrm{pH} 5.20$ and the growth of $L$. acidophilus was inhibited except that of DS 910. Therefore, MRS agar at $\mathrm{pH} 5.20$, under anaerobic incubation at $43^{\circ} \mathrm{C}$ could be selective for $L$. delbrueckii ssp. bulgaricus if $L$. rhamnosus and L. acidophilus DS 910 were not present in a product. The colony morphology of $L$. delbrueckii ssp. bulgaricus and L. rhamnosus was very different and these two organisms could be easily differentiated if $L$. rhamnosus was present in the product.

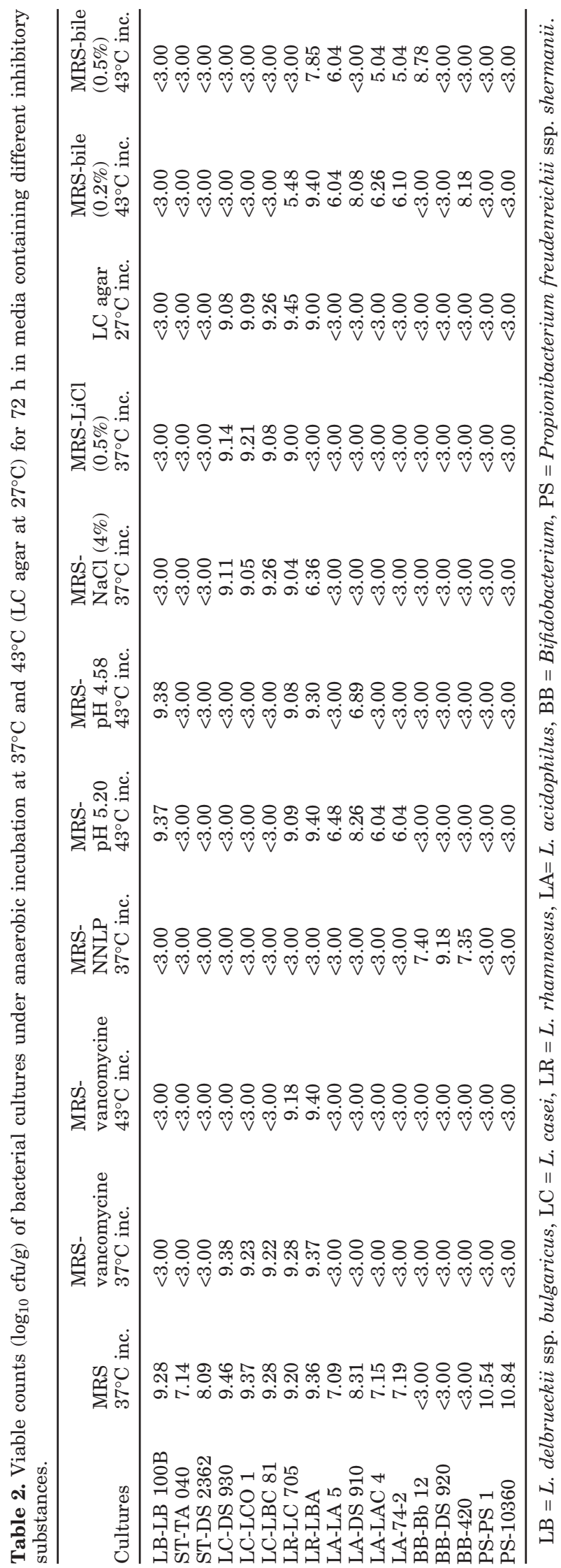

Journal of Dairy Science Vol. 86, No. 7, 2003 
Table 3. Viable counts $\left(\log _{10} \mathrm{cfu} / \mathrm{g}\right)$ of bacterial cultures in different sugar based media under aerobic incubation at $43^{\circ} \mathrm{C}$ for $72 \mathrm{~h}$.

\begin{tabular}{|c|c|c|c|c|c|}
\hline Cultures & MRS & $\mathrm{BA}^{1}$-sorbitol & BA-manitol & BA-maltose & BA-esculin \\
\hline LB-LB 180 & 7.95 & $<3.00$ & $<3.00$ & $<3.00$ & $<3.00$ \\
\hline ST-DS 2362 & 8.00 & $<3.00$ & $<3.00$ & $<3.00$ & $<3.00$ \\
\hline ST-TA 040 & 7.69 & $<3.00$ & $<3.00$ & $<3.00$ & $<3.00$ \\
\hline LC-LCO 1 & $<3.00$ & $<3.00$ & $<3.00$ & $<3.00$ & $<3.00$ \\
\hline LC-LBC 81 & $<3.00$ & $<3.00$ & $<3.00$ & $<3.00$ & $<3.00$ \\
\hline LR-LC 705 & 9.30 & 9.28 & 9.24 & 9.31 & 9.13 \\
\hline LR-LBA & 9.36 & 9.32 & 9.30 & 9.36 & 9.46 \\
\hline LA-DS 930 & $<3.00$ & $<3.00$ & $<3.00$ & $<3.00$ & $<3.00$ \\
\hline LA-LA 5 & 6.48 & $<3.00$ & $<3.00$ & $<3.00$ & $<3.00$ \\
\hline LA-DS 910 & 7.60 & $<3.00$ & $<3.00$ & 7.08 & 7.27 \\
\hline LA-74-2 & 8.93 & $<3.00$ & 4.00 & 8.27 & 8.45 \\
\hline BB-Bb 12 & $<3.00$ & $<3.00$ & $<3.00$ & $<3.00$ & $<3.00$ \\
\hline BB-DS 920 & $<3.00$ & $<3.00$ & $<3.00$ & $<3.00$ & $<3.00$ \\
\hline BB- 420 & $<3.00$ & $<3.00$ & $<3.00$ & $<3.00$ & $<3.00$ \\
\hline BB-BL & $<3.00$ & $<3.00$ & $<3.00$ & $<3.00$ & $<3.00$ \\
\hline
\end{tabular}

\footnotetext{
${ }^{1}$ Basal agar, $\mathrm{LB}=L$. delbrueckii $\mathrm{ssp}$. bulgaricus, $\mathrm{ST}=S$. thermophilus, $\mathrm{LA}=$ L. acidophilus, $\mathrm{LC}=L$. casei,
} $\mathrm{LR}=$ L. rhamnosus, $\mathrm{BB}=$ Bifidobacterium.

Therefore, $\mathrm{pH}$ modified MRS ( $\mathrm{pH}$ 4.58) agar and anaerobic incubation at $43^{\circ} \mathrm{C}$ could be used to selectively enumerate $L$. delbrueckii ssp. bulgaricus from a product.

L. casei grew in $\mathrm{MRS}-\mathrm{NaCl}(4 \%), \mathrm{MRS}-\mathrm{LiCl}(0.5 \%)$ at $37^{\circ} \mathrm{C}$ under anaerobic incubation and LC agar. L. casei did not grow in NNLP agar and at $43^{\circ} \mathrm{C}$. Lower incubation temperatures $\left(\leq 37^{\circ} \mathrm{C}\right)$ supported the growth of $L$. casei. L. casei and L. rhamnosus were resistant to 1 $\mathrm{mg}$ vancomycine/L. L. rhamnosus formed well developed smooth white discs like colonies that were $2 \mathrm{~mm}$ or more in diameter in MRS-vancomycine (MRS-V) agar at $37^{\circ} \mathrm{C}$ under anaerobic incubation. L. rhamnosus grew at both incubation temperatures of $37^{\circ} \mathrm{C}$ and $43^{\circ} \mathrm{C}$ and in all sugar based media under aerobic and anaerobic conditions, except in MRS-NNLP agar and showed varying growth pattern (between strains) in MRS-bile agar, and MRS-LiCl agar. The organisms grew well in MRS-V agar at both incubation temperatures of $37^{\circ} \mathrm{C}$ and $43^{\circ} \mathrm{C}$ as well as in LC agar at $27^{\circ} \mathrm{C}$. MRS-V agar at $43^{\circ} \mathrm{C}$ and anaerobic incubation supported the growth of only $L$. rhamnosus. No other cultures tested including $L$. delbrueckii ssp. bulgaricus, $S$. thermophilus, L. casei, L. acidophilus, Bifidobacterium lactis and Propionibacterium grew in this medium.

Basal agar (BA)-sorbitol agar and BA-mannitol agar under aerobic incubation at $43^{\circ} \mathrm{C}$ (Table 3 ) and BA-sorbitol agar and BA-mannitol agar at $43^{\circ} \mathrm{C}$ and anaerobic incubation (data not shown) also supported the growth of only L. rhamnosus. Therefore, MRS-V agar at $43^{\circ} \mathrm{C}$ under anaerobic incubation, BA-sorbitol agar, or BAmannitol agar at $43^{\circ} \mathrm{C}$, either under aerobic or anaerobic incubations, were selective for $L$. rhamnosus.

MRS-V agar at $37^{\circ} \mathrm{C}$ or $\mathrm{LC}$ agar at $27^{\circ} \mathrm{C}$ under anaerobic incubation (Table 2) could be selective for $L$. casei when $L$. rhamnosus was not present in a product. When
L. rhamnosus was present, total counts of $L$. casei and L. rhamnosus could be obtained using MRS-V agar at $37^{\circ} \mathrm{C}$ and anaerobic incubation for $72 \mathrm{~h}$. The count of L. rhamnosus on MRS-V agar at $43^{\circ} \mathrm{C}$ and anaerobic incubation for $72 \mathrm{~h}$ could be subtracted from the total counts of $L$. casei and L. rhamnosus to obtain the counts of $L$. casei.

MRS-NNLP agar (which contains $0.05 \%$ L-cysteine in the formula) at $37^{\circ} \mathrm{C}$ and anaerobic incubation supported the growth of only bifidobacteria (Table 2). When L-cysteine was not present in the media, bifidobacteria either did not grow or formed pinpoint colonies (data not shown). Therefore, MRS-NNLP agar with $0.05 \%$ L-cysteine and anaerobic incubation at $37^{\circ} \mathrm{C}$ were selective for bifidobacteria and the absence of L-cysteine was able to control the growth of bifidobacteria from other media.

Table 4 shows the colony counts and colony sizes of various bacterial cultures in different agar media. Colonies of $\geq 0.5 \mathrm{~mm}$ in diameter were only counted as developed colonies for the enumeration purpose. NaLa agar, arabinose agar, raffinose agar, and xylose agar supported the growth of $L$. casei, $L$. acidophilus, and $L$. rhamnosus as well as of propionibacteria. In these media, $L$. casei and $L$. rhamnosus formed white shiny smooth colonies of $1 \mathrm{~mm}$ diameter.

Propionibacteria formed colonies of $0.5 \mathrm{~mm}$ diameter in all the media. However, in NaLa agar, propionibacteria formed colonies that were dull brown with lighter margin of 1.0 to $2.5 \mathrm{~mm}$ in diameter. The colonies were very different to those formed by $L$. casei and $L$. rhamnosus. L. acidophilus formed pinpoint colonies. To eliminate the possibility of $L$. acidophilus being counted, colonies of $\geq 0.5 \mathrm{~mm}$ diameter were only counted. Proper colonies of propionibacteria formed only after $72 \mathrm{~h}$ of incubation and after $7 \mathrm{~d}$ colony size grew to $2 \mathrm{~mm}$ in 
diameter. The colony sizes of $L$. casei and $L$. rhamnosus did not change. In NaLa agar, the recovery was the highest and colony morphology and colony size were different than those formed in arabinose agar, and xylose agar. Thus, NaLa agar could be used to selectively enumerate propionibacteria. The propionibacteria could also be counted by subtracting the counts of $L$. casei and $L$. rhamnosus at day 3 from the total counts of $L$. casei, $L$. rhamnosus and propionibacteria obtained on d 7 using NaLa agar, raffinose agar or xylose agar (Table 4).

$L$. acidophilus was found to be the most difficult to enumerate selectively, since most of the media that supported the growth of $L$. acidophilus also supported the growth of $L$. casei and $L$. rhamnosus. When the incubation temperature was increased to $43^{\circ} \mathrm{C}, L$. casei was eliminated. However, L. rhamnosus still formed well developed ( $1.5 \mathrm{~mm}$ in diameter) colonies and $L$. acidophilus formed smaller colonies ( 0.1 to $1.0 \mathrm{~mm}$ ) depending on the sugar used (Table 1). When galactose was used, bifidobacteria formed pinpoint colonies in the absence of L-cysteine, and the colonies could be confused with $L$. acidophilus. L. delbrueckii ssp. bulgaricus and S. thermophilus formed colonies in MRS agar when incubated anaerobically at $43^{\circ} \mathrm{C}$. Therefore, MRS agar and anaerobic incubation at $43^{\circ} \mathrm{C}$ could be used to enumerate $L$. acidophilus when $L$. delbrueckii ssp. bulgaricus and $S$. thermophilus were not present in the product (data not shown).

When incubated anaerobically at $43^{\circ} \mathrm{C}$ in BA-mannitol agar, BA-sorbitol agar, BA-esculin agar and BA-maltose agar, L. rhamnosus formed large (2.0 to $2.5 \mathrm{~mm}$ diameter) smooth shiny disc like colonies (data not shown), while $L$. acidophilus formed smaller (0.1 to $1.0 \mathrm{~mm}$ diameter) rough dull colonies. BA-maltose agar supported the growth of $L$. acidophilus more than the other BA-based agar media at this incubation temperature, but one strain of L. acidophilus DS 910 formed large colonies that could be confused with $L$. rhamnosus. In MRS agar, L. delbrueckii ssp. bulgaricus, S. thermophilus, L. rhamnosus and $L$. acidophilus formed colonies (Table 3 ) while in BA-maltose agar, only L. acidophilus and L. rhamnosus formed colonies. L. rhamnosus formed large (2.0 to $2.5 \mathrm{~mm}$ diameter) smooth, shiny, and disc like colonies, while strains of $L$. acidophilus formed smaller rough brownish colonies of 0.1 to $1.0 \mathrm{~mm}$ diameter that could be easily distinguished. Therefore, MRS agar under aerobic or anaerobic incubation at $43^{\circ} \mathrm{C}$ could be used to count L. acidophilus, except DS 910, when L. delbrueckii ssp. bulgaricus was not present in the product. If $L$. delbrueckii ssp. bulgaricus is present, BA-maltose agar and anaerobic incubation at $43^{\circ} \mathrm{C}$ could be used and only small rough brownish colonies should be counted as $L$. acidophilus. 
Table 5. Media recommended for selective enumeration of Streptococcus thermophilus, Lactobacillus delbrueckii ssp. bulgaricus, Lactobacillus acidophilus, Bifidobacterium, Lactobacillus casei, Lactobacillus rhamnosus, and propionibacteria and viable counts of in a mixture of bacteria.

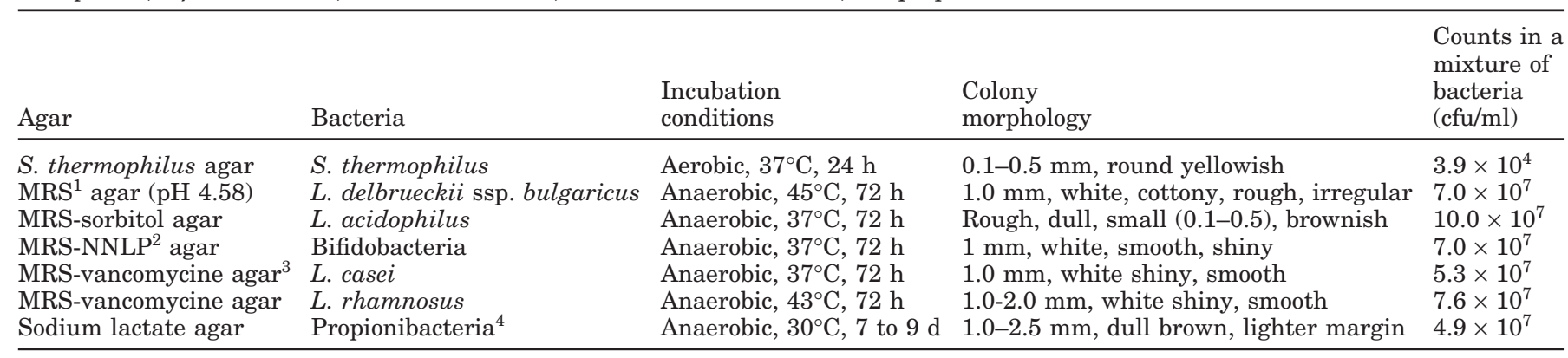

${ }^{1}$ deMan, Rogosa, and Sharpe agar.

${ }^{2}$ Nalidixic acid, neomycin sulfate, lithium chloride, and paromomycin sulfate.

${ }^{3}$ If $L$. rhamnosus was not present; however, if $L$. rhamnosus was present, then subtraction methods could be used (i.e., subtracting $L$. rhamnosus counts on MRS-vancomycine agar under anaerobic incubation at $43^{\circ} \mathrm{C}$ for $72 \mathrm{~h}$ from total counts of L. casei and L. rhamnosus obtained in MRS-vancomycine agar under anaerobic incubation at $37^{\circ} \mathrm{C}$ for $72 \mathrm{~h}$ ).

${ }^{4}$ Subtraction method could also be used to determine the counts of propionibacteria (i.e., counts of $L$. casei and L. rhamnosus (anaerobic incubation, $30^{\circ} \mathrm{C}, 72 \mathrm{~h}$ ) could be subtracted from counts of L. casei, L. rhamnosus, and propionibacteria (anaerobic incubation, $30^{\circ} \mathrm{C}, 7 \mathrm{~d}$ ).

Among the media tested for L. acidophilus, BA-sorbitol agar gave the highest recovery (Table 1). In this medium, L. casei and L. rhamnosus formed shiny, large, smooth and white colonies, while all strains of $L$. acidophilus tested formed rough dull, small, and brownish colonies. Therefore, only the small dull rough brownish colonies should be enumerated as the counts of $L$. acidophilus.

Table 5 summarizes the media that could be used for selective enumeration of the seven groups of bacteria and their incubation conditions and colony morphology. To verify the efficacy of the method selected in this study, mixtures of $L$. delbrueckii ssp. bulgaricus, $S$. thermophilus, L. acidophilus, bifidobacteria, L. casei, L. rhamnosus, and propionibacteria cells were added at approximately $10^{7} \mathrm{cfu} / \mathrm{ml}$ in the ratio of $0.1,0.5,4,2,1,1$, and 1 , respectively, and the organisms were plated in the media under incubations outlined in Table 5. The identity of each organism was verified by biochemical tests (Kandler and Weiss, 1986). The results are presented in Table 5. As shown in the table, the media were discriminatory for the various groups of bacteria. Thus it appears that the methods could be used for selective enumeration of the seven groups of bacteria used in this study.

\section{Enumeration of Bacteria in Commercial Products}

Because the evaluation of media for selective enumeration of yogurt and probiotic bacteria was carried out using pure cultures, it was desirable to validate the efficacy of the method selected using commercial products. Five brands of commercial yogurts and one brand of Swiss cheese were purchased from a local super market, and their bacterial populations analyzed using the different selective bacteriological media. Enumeration of $S$. thermophilus was carried out using ST agar and aerobic incubation at $37^{\circ} \mathrm{C}$ for 24 h. L. delbrueckii ssp. bulgaricus was enumerated using MRS-agar ( $\mathrm{pH} 4.58$ ) and anaerobic incubation at $45^{\circ} \mathrm{C}$ for $72 \mathrm{~h}$. For L. rhamnosus, MRS$\mathrm{V}$ agar and anaerobic incubation at $43^{\circ} \mathrm{C}$ were used. $L$. casei was enumerated using subtraction method, in which viable counts of $L$. rhamnosus on MRS-V agar at $43^{\circ} \mathrm{C}$ under anaerobic incubation were subtracted from the total counts of $L$. casei and L. rhamnosus on MRS$\mathrm{V}$ at $37^{\circ} \mathrm{C}$ under anaerobic incubation. Bifidobacteria were enumerated on MRS-NNLP agar. Enumeration of L. acidophilus was carried out using BA-sorbitol agar at $37^{\circ} \mathrm{C}$ and anaerobic incubation for $72 \mathrm{~h}$, and BA-maltose agar and anaerobic incubation at $43^{\circ} \mathrm{C}$ for $72 \mathrm{~h}$. Only the small rough brownish colonies $(0.1$ to $0.5 \mathrm{~mm}$ ) were counted as $L$. acidophilus. Propionibacteria were enumerated by subtracting the counts at $d 3$ of lactic acid bacteria on NaLa agar and anaerobic incubation at $30^{\circ} \mathrm{C}$ from the total counts of lactic acid bacteria and propionibacteria at day 7 .

Table 6 shows the organisms claimed to be present in commercial products and the actual recovery of the organisms. S. thermophilus was present in all of yogurts tested. L. delbrueckii ssp. bulgaricus was present only in product 5 (skinny yogurt). Many commercial products are manufactured using $L$. acidophilus, bifidobacteria and $S$. thermophilus cultures, which do not contain $L$. delbrueckii ssp. bulgaricus. L. casei was claimed to be present in both products 4 and 5 , however, only product 4 (natural yogurt) showed reasonable population of this organism. The stage of shelf life and the $\mathrm{pH}$ of yogurt might have affected the viability of the probiotic organism.

Product 2 (natural yogurt) and product 3 (flavored yogurt) had high counts of all organisms claimed including $S$. thermophilus, L. rhamnosus, L. acidophilus, and 


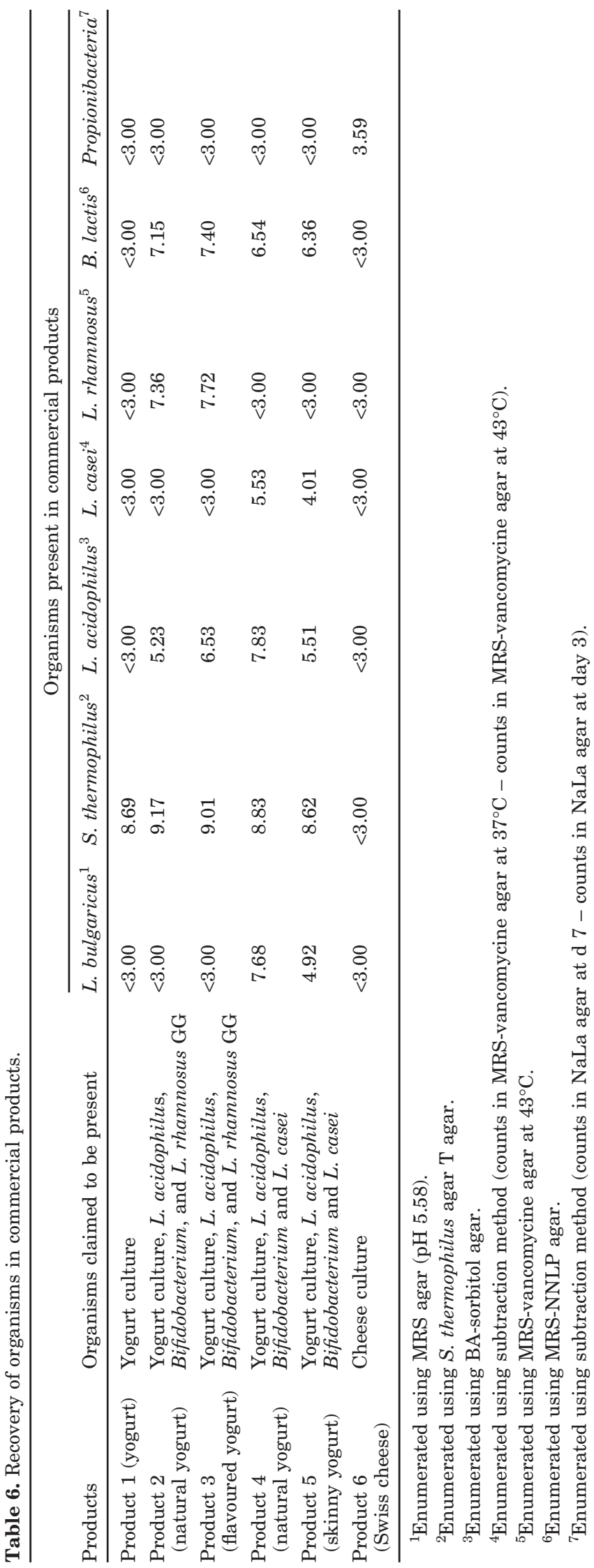

bifidobacteria. Products 2 and 3 contained $L$. rhamnosus. Bifidobacteria were found in products 4 and 5 and products 2 and 3 in high concentrations $\left(10^{6}\right.$ to $\left.10^{7}\right)$. L. acidophilus also was found in appreciable concentration in all yogurt claimed to contain this organism. Propionibacteria were only found in Swiss cheese (product 6) and this was the only product that claimed to contain propionibacteria. The identity of the organisms was confirmed using Gram stain. Thus it appears that the enumeration methods developed and selected in this study were suitable for enumeration of $S$. thermophilus, $L$. delbrueckii ssp. bulgaricus, L. casei, L. rhamnosus, L. acidophilus, bifidobacteria and propionibacteria.

\section{CONCLUSIONS}

In this study 19 bacteriological media were evaluated under different incubation conditions for their suitability to recover and enumerate 7 species containing 18 strains of bacteria including $L$. delbrueckii ssp. bulgaricus, $S$. thermophilus, L. casei, L. rhamnosus, L. acidophilus, bifidobacteria, and propionibacteria. The evaluation was based on sugar fermentation patterns, use of inhibitory substances (such as acid, bile, salt and antibiotics), different incubation temperatures $\left(27,30,37,43\right.$, and $\left.45^{\circ} \mathrm{C}\right)$, incubation conditions (such as aerobic and anaerobic) and the duration of incubation $(24,72 \mathrm{~h}$, or 7 to $9 \mathrm{~d})$. ST agar under aerobic incubation at $37^{\circ} \mathrm{C}$ for $24 \mathrm{~h}$ was suitable for $S$. thermophilus. L. delbrueckii ssp. bulgaricus could be enumerated using MRS agar ( $\mathrm{pH}$ 4.58) and anaerobic incubation at $45^{\circ} \mathrm{C}$ for $72 \mathrm{~h}$. MRS-vancomycine agar and anaerobic incubation for $72 \mathrm{~h}$ at $43^{\circ} \mathrm{C}$ were suitable for enumeration of $L$. rhamnosus. MRS-vancomycine agar and anaerobic incubation at $37^{\circ} \mathrm{C}$ for $72 \mathrm{~h}$ or LC agar at $27^{\circ} \mathrm{C}$ for $72 \mathrm{~h}$ and anaerobic incubation were selective for enumeration of $L$. casei, when L. rhamnosus was not present in the mixture. $L$. casei could also be enumerated by subtraction method if $L$. rhamnosus was present in the product. The counts of $L$. rhamnosus on MRS-vancomycine agar under anaerobic incubation at $43^{\circ} \mathrm{C}$ for $72 \mathrm{~h}$ could be subtracted from total counts of $L$. casei and L. rhamnosus on MRS-vancomycine agar at $37^{\circ} \mathrm{C}$ for $72 \mathrm{~h}$ under anaerobic incubation to obtain $L$. casei count. Bifidobacteria could be enumerated on MRSNNLP agar. The most suitable method for counting propionibacteria was by subtracting the counts at $d 3$ of all bacteria except propionibacteria on NaLa agar under anaerobic incubation at $30^{\circ} \mathrm{C}$ from the total counts at $\mathrm{d}$ 7 of all bacteria including propionibacteria under same incubation conditions. Counting large (1.0 to $2.5 \mathrm{~mm}$ diameter), smooth brownish colonies with lighter margin on sodium lactate agar after 7 to $9 \mathrm{~d}$ at $30^{\circ} \mathrm{C}$ under anaerobic incubation could also be used to count propionibacteria. L. acidophilus could be enumerated on BA- 
sorbitol agar at $37^{\circ} \mathrm{C}$ for $72 \mathrm{~h}$ under anaerobic incubation or MRS-agar at $43^{\circ} \mathrm{C}$ for $72 \mathrm{~h}$ under anaerobic incubation or BA-maltose agar at $43^{\circ} \mathrm{C}$ under anaerobic incubation.

\section{ACKNOWLEDGMENTS}

The authors are grateful to the late Mr. Chris Saristavrou, the founder of Poseidon Tarama Ltd. for allowing this project to be carried out at Poseidon Tarama Ltd. We are also thankful to Mr. John Batzias, Technical Director, Poseidon Tarama Ltd. for his support.

\section{REFERENCES}

Champagne, C. P., D. Roy, and A. Lafond. 1997. Selective enumeration of Lactobacillus casei in yoghurt-type fermented milks based on a $15^{\circ} \mathrm{C}$ incubation temperature. Biotechnol. Tech. 11:567-569.

Dave, R. I., and N. P. Shah. 1996. Evaluation of media for selective enumeration of Streptococcus thermophilus, Lactobacillus delbrueckii ssp. bulgaricus, Lactobacillus acidophilus and bifidobacteria. J. Dairy Sci. 79:1529-1536.

Fuller, R. 1992. Probiotics-The Scientific basis. Chapman and Hall, London.

Hull, R. R., and A. V. Roberts. 1984. Differential enumeration of Lactobacillus acidophilus in yoghurt. Aust. J. Dairy Technol. 39:160163.
Hunger, W. 1986. Aesculin-cellobiose agar for the isolation and counting of Lactobacillus acidophilus. Milchwissenschaft 41:283-285.

Kandler, O., and N. Weiss. 1986. Regular, non-sporing Gram-positive rods. Page 1222 in Bergey's Manual of Systematic Bacteriology. Vol. 2, P.H. Sheath, N.S. Mair, M.E. Sharpe, and J.G. Holt, ed., Williams and Wilkins Publ. Baltimore, MD.

Lankaputhra, W. E. V., and N.P. Shah. 1996. A simple method for selective enumeration of Lactobacillus acidophilus in yoghurt supplemented with L. acidophilus and Bifidobacterium spp. Milchwissenschaft 51:446-451.

Laroia, S., and J. H. Martin. 1991. Methods for enumerating and propagating bifidobacteria. Cult. Dairy Prod. J. 26:32-33.

Onggo, I., and G. H. Fleet. 1993. Media for the isolation and enumeration of lactic acid bacteria from yoghurts. Aust. J. Dairy Technol. 48:89-92.

Ravula, R. R., and N. P. Shah. 1998. Selective enumeration of Lactobacillus casei from yogurt and fermented milk drinks. Biotechnol. Tech. 12:819-822.

Samona, A., and R. K. Robinson. 1994. Effect of yoghurt cultures on the survival of bifidobacteria in fermented milks. J. Soc. Dairy Technol. 47:58-60.

Shah, N. P. 1997. Isolation and enumeration of bifidobacteria in fermented milk products: A review. Milchwissenschaft 52:71-76.

Shah, N. P. 2000. Probiotic bacteria: Selective enumeration and survival in dairy foods. J. Dairy Sci. 83:894-907.

Shah, N. P., and P. Jelen. 1990. Survival of lactic acid bacteria and their lactases under acidic conditions. J. Food Sci. 55:506-509.

Wijsman, M. R., L. P. Johanna, M. Hereijgers, and J. M. F. H. Groote. 1989. Selective enumeration of bifidobacteria in fermented dairy products. Neth. Milk Dairy J. 43:395-405. 